\title{
Familial cerebellar ataxia presenting with down beat nystagmus
}

\author{
G D SCHOTT \\ From The National Hospital for Nervous Diseases, Queen Square, London WC1N 3BG
}

SUMMARY Two brothers are described who during their fourth decade presented with isolated down beat nystagmus and later developed a progressive cerebellar ataxia. The nature of this unusual oculomotor disorder and its rare occurrence in other inherited conditions are discussed.

Down beat nystagmus is characterised by vertical jerk nystagmus in which the fast phase occurs in a downward direction. It is an uncommon manifestation of disorders in the region of the craniocervical junction and is seen with a variety of structural lesions at that site. The present report describes this oculomotor disorder in two brothers as the presenting feature of a late onset, probably autosomal recessive, cerebellar ataxia.

\section{Case reports}

\section{CASE 1}

The proband (III-2) first attended the National Hospital, Queen Square at the age of 42, complaining of 5 years' intermittent difficulty in focusing. Occasional vertical oscillopsia and transient diplopia had occurred over the same period, and an optician had detected nystagmus. His brother, 7 years younger, has a similar disorder. The pedigree is illustrated in the figure. The brothers' unaffected parents, who were unrelated, died in their seventies.

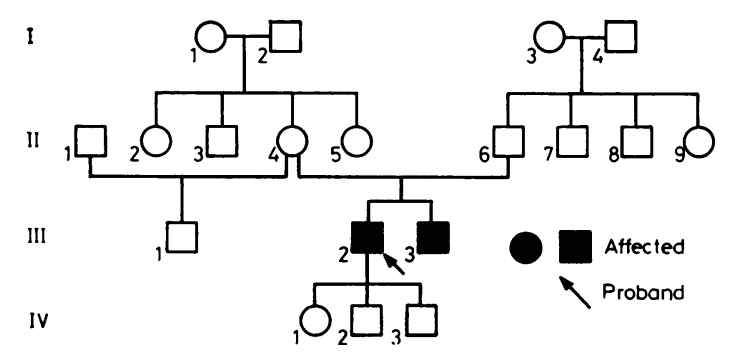

FIGURE Family pedigree.

Received for publication 22 June 1979
Examination at this time was unremarkable except for the finding of second degree down beat nystagmus, which increased in velocity on gaze to the left and right; the nystagmus was unaltered on changes of posture. Eye movements were full but, while voluntary saccadic movements were normal, following movements were markedly broken up by the nystagmus. Optokinetic responses were present on rotation of the drum to the left and right, producing nystagmus in an oblique, downward direction which was attributable to the superimposed down beat vertical nystagmus. No optokinetic nystagmus was produced in the vertical direction. Electronystagmography confirmed spontaneous down beat vertical nystagmus, vestibular in character, which was inhibited by eye closure and darkness, and was consistent with a central disturbance of the vestibular system or its connections. ${ }^{1}$ Caloric responses were absent. The pure tone audiogram was normal.

Six years later at the age of 48 he was admitted for assessment of a 4-year history of progressive imbalance of gait. His walking had become unsteady, particularly on turning, and for 2 years he had noticed slight slurring of speech and difficulty in swallowing. He managed a clerical job and was able to use public transport without difficulty.

On examination his slight slurring dysarthria was confirmed. His gait was ataxic, he walked with a wide base, and had difficulty in turning without losing balance. Tongue movements were slightly slow. The tendon reflexes were unusually brisk but there were no pathological reflexes. Nystagmus, similar to that noted earlier, was again found; pursuit eye movements were found to be grossly broken up by nystagmus though voluntary movements were normal. Ocular dysmetria was detected on occasions. Neither intellectual deficit nor 
emotional changes were evident and general examination was unremarkable.

Neuro-otological findings were unchanged compared with those obtained previously. Formal psychological assessment showed no evidence of intellectual impairment. The blood picture, plasma electrolytes and urea, blood sugar, serum cholesterol and vitamin $\mathbf{B}_{12}, x$-rays of chest, skull, and cervical spine, and electroencephalogram were normal. The Wassermann reaction in blood and CSF was negative. An air encephalogram showed considerable excess of air surrounding the cerebellum together with some enlargement of the cortical spaces over the hemispheres, indicating cerebellar and slight cerebral atrophy; there was no evidence of a lesion in the region of the foramen magnum. The CSF was normal apart from a slightly raised protein of $0.6 \mathrm{~g} / 1$.

When seen again at the age of 53 , his ataxic gait had progressed. He had become largely chair-bound for 2 years, required a frame for walking around his house, and needed support when standing. Over the same period he had become 'clumsy' and had difficulty carrying out fine finger movements. His speech had become slurred and swallowing was increasingly difficult. Examination showed the same nystagmus, but more marked ataxia of arms and legs and hypotonia in the limbs with slowed fine finger movements bilaterally. The tendon reflexes, however, were all markedly exaggerated with prominent finger jerks and crossed adductor responses in the legs. The plantar responses remained flexor and sensory examination was normal.

CASE 2

His brother (III.3) had been seen at the age of 37 years for a short history of 'eye strain'. This symptom was associated with intermittent oscillopsia and transient variable diplopia, and at that time down beat nystagmus had been detected without other neurological or ophthalmological signs. When aged 45, he was admitted for investigation of a 3-year history of ataxia of gait. He complained of progressive unsteadiness of walking with occasional falls, intermittent sensations of disequilibrium, and a need to use the banisters to steady himself when climbing stairs. For 2 years he had noted slight slurring of speech and occasional difficulty in swallowing. On examination, spontaneous second degree down beat jerk nystagmus was evident, which increased on lateral gaze in either direction and on down gaze and was unaffected by changes in posture. Eye movements were full but pursuit movements were again broken up. With the optokinetic drum a horizontal component was superimposed on the vertical down beat nystagmus on horizontal rotation of the drum vertical nystagmus persisted irrespective of rotation of the drum in the upward or downward direction Slow palatal movements were evident as was slight slurring dysarthria. Tone was slightly increased in both legs and unsustained ankle clonus could be elicited. There was slight intention tremor of the left arm and his gait was grossly ataxic. He coule barely stand with his feet together and was unable to perform tandem walking. He tended to deviate tक्ठ the left when walking which he did using a wide base. The limb reflexes were markedly exaggerated butt there were no pathological reflexes and abdominas responses were retained. Sensory examination wa․ normal.

Electronystagmography showed the same features that had been found in his brother and calorie responses were also absent. The following ingr vestigations were normal: blood picture, serur? electrolytes and urea, blood sugar, SMA 12 metabolic screen, serum thyroxine, CSF, electroencephalo? gram, visual evoked responses, sensory nerve cone. duction studies in arms and legs, and pure tong audiogram. The electrocardiogram was normage apart from non-specific $T$ wave inversion in leads 3 and AVF. $X$-rays of the spine and skull including foramen magnum views were also normal. Bloo and CSF serological tests for syphilis were negative Performed to exclude malformations at the cranioo cervical junction, a Myodil myelogram with examination both prone and supine showed $n \vec{\Theta}$ abnormality apart from widening of the fourtB ventricle. A urine metabolic screen, including estimation of cystine, homocystine, mucopoly? saccharides, and creatinine, and sugar and amino ${ }_{\overline{3}}$ acid chromatography were normal, as was plasm amino-acid chromatography. Psychological assess? ment showed no evidence of intellectual impairmen

\section{Discussion}

The two brothers described in the present report show a very similar disorder, characterised by the onset of rather ill-defined ocular symptoms such ass 'difficulty in focusing' and 'eye strain'. These symptoms were noted by both brothers independentl他 towards the end of their fourth decade, and were followed a few years later by a progressive cerebella里 disorder with ataxia of gait and slurring dysarthria Slight dysphagia had also been noted independentlo by both patients. Down beat nystagmus was detected at the time of initial medical presentation, and therd can be no doubt that this striking disturbance of eyo movement antedated the more typical cerebellas features by some time. Indeed both patients wers specifically examined at their initial presentation to 
assess the presence of any neurological disorder, and no abnormality other than nystagmus had been detected. In addition to the cerebellar dysfunction, the dysphagia with slowed tongue movements and pathologically increased reflexes are suggestive of additional mild bilateral corticospinal tract involvement; this enables the disorder to be included among the poorly delineated late onset hereditary ataxias, ${ }^{2}$ in which corticospinal tract involvement frequently occurs, and spinocerebellar degenerations. $^{3}$

The occurrence of such a similar condition in two brothers makes an inherited condition most likely, and with sex linked cerebellar degenerations being particularly uncommon, ${ }^{4}$ an autosomal recessive mode of inheritance appears more probable. The brothers' parents both died at an age when, were they to have become affected in a similar fashion, the disorder would have become manifest, so that a dominant inheritance is unlikely. The almost identical chronological development of the symptoms in the brothers and the length of history, together with the lack of evidence on investigation of any structural disorder at the craniocervical junction, exclude the commoner lesions at that site which may cause a cerebellar syndrome with down beat nystagmus (see below). Recalling that some of the skeletal disorders mentioned later may themselves be inherited, ${ }^{56}$ and particularly with only two members of the family being affected, appropriate investigation was considered necessary to exclude a potentially treatable condition.

Although ocular disturbances such as pupil abnormalities and ophthalmoplegia have been recorded in cerebellar degenerations, ${ }^{7}$ nystagmus, which is usually horizontal, is a classical but variable feature, the complexities of which have been shown by detailed physiological studies of vestibulo-ocular function. ${ }^{8}$ It is of interest that while visual symptoms such as oscillopsia are often not a striking feature of horizontal nystagmus, they are often complained of in the presence of down beat nystagmus, as with the patients described here. Also noteworthy is that while both brothers exhibited prominent cerebellar signs, caloric testing showed absent responses, despite the observation that these are often enhanced in cerebellar disease. ${ }^{9}$

Usually considered pathognomonic of a lesion at the craniocervical junction, down beat nystagmus was considered in 1968 by $\operatorname{Cogan}^{10}$ in the first important review of the subject. In an analysis of 27 cases of down beat nystagmus, eight patients were found to have platybasia or the Arnold-Chiari malformation, but various other causes including multiple sclerosis, syphilis, and neoplasm were also identified. A number of other patients have been described in whom craniocervical skeletal abnormalities have appeared as underlying causes. ${ }^{11} 12$ In some instances, as in six patients of Cogan's series ${ }^{10}$, despite full investigation and observation over a prolonged period, no cause for the nystagmus has become evident. The recent report of down beat nystagmus occurring as a manifestation of anticonvulsant toxicity is noteworthy. ${ }^{13}$

Down beat nystagmus has rarely been described as a component of hereditary cerebellar ataxia. Zee et $a l^{14}$ reported a family with late onset, dominantly inherited, cerebellar ataxia with a variety of oculomotor abnormalities, down beat nystagmus being but one manifestation. Brisk reflexes were sometimes observed. In these and other cases, however, ataxia appears invariably to have been the first feature and visual complaints have been inconstant, clearly distinguishing them from the present cases in which isolated down beat nystagmus occurred early and was the sole presenting feature. Other inherited disorders in which unspecified vertical nystagmus occurs have also been recorded. For instance recurrent attacks of vertigo, diplopia, and ataxia with 'vertical' nystagmus between attacks, later followed by progressive cerebellar ataxia have been described as an autosomal dominant condition. ${ }^{15}$ Vertical nystagmus has been noted as a very rare congenital and occasionally inherited condition, sometimes associated with mild ataxia. When reviewed by Marmor, ${ }^{16}$ five families had been collected personally and from published reports; an autosomal dominant pattern of inheritance occurred in three families, that in two being uncertain. Although up beat nystagmus was reported more commonly, down beat nystagmus also occurred (for example, Marmor, ${ }^{16}$ family 1 , case 5 ). In this form of congenital nystagmus, while mild ataxia may be present, the condition is non-progressive and benign.

Although the cerebellum and lower brain stem are likely to be implicated in the production of down beat nystagmus, and mechanisms responsible for it have been investigated, ${ }^{17}$ its cause remains unclear. It is of practical importance, however, that this oculomotor sign may not only point to a definable and possibly treatable structural lesion in the region of the craniocervical junction, but may also occur in isolation and long precede the subsequent development of an inherited spinocerebellar degeneration.

I am indebted to Dr C J Earl and Dr J D Parkes for permission to publish details of patients under their care, to Dr J D Hood for valuable discussion on the neuro-otological aspects, and to $\mathrm{Dr} \mathrm{M}$ Baraitser for kindly reviewing the manuscript. 


\section{References}

1 Hood JD. Recent advances in the electronystagmographic investigation of vestibular and other disorders of ocular movement. In: de Reuck AVS, Knight J, eds. Ciba Foundation Symposium on Myotactic, Kinesthetic and Vestibular Mechanisms. London: Churchill, 1967: 252-64.

2 Kark RAP, Rosenberg RN, Schut LJ, eds. The inherited ataxias. Advances in neurology. vol 21. New York: Raven Press, 1978.

${ }^{3}$ Greenfield JG. The spinocerebellar degenerations. Oxford: Blackwell, 1954.

4 Spira PJ, McLeod JG, Evans WA. A spinocerebellar degeneration with X-linked inheritance. Brain 1979;102: 27-41.

5 Scoville, WB, Sherman IJ. Platybasia. Ann Surg 1951; 133:496-502.

- Bull JWD, Nixon WLB, Pratt RTC. The radiological criteria and familial occurrence of primary basilar impression. Brain 1955;78:229-47.

7 Tyrer JH, Sutherland JM. The primary spino-cerebellar atrophies and their associated defects, with a study of the foot deformity. Brain 1961;84:289-300.

8 Baloh RW, Konrad HR, Honrubia V. Vestibulo-ocular function in patients with cerebellar atrophy. Neurology (Minneap) 1975; 25:160-8.
- Rudge P. The auditory and vestibular systems-auditor evoked potentials and vestibulo-ocular disorders. In: Matthews WB, Glaser GH, eds. Recent advances $i \overrightarrow{\bar{\pi}}$ clinical neurology. No 2. Edinburgh, London, New York? Churchill Livingstone, 1978:83.

10 Cogan DG. Down-beat nystasmus. Arch Neurol 1968응 80:757-68

11 Hart JCD, Sanders MD. Downbeat nystagmus. Tran Ophthalmol Soc UK 1970; 90:483-90.

12 Spillane JD, Pallis C, Jones AM. Developmental ab normalities in the region of the foramen magnum. Brain $1957 ; 80: 11-48$.

13 Alpert JN. Downbeat nystagmus due to anticonvulsant toxicity. Ann Neurol 1978;4:471-3.

14 Zee DS, Yee RD, Cogan DG, Robinson DA, Engel WK Ocular motor abnormalities in hereditary cerebella $\bar{B}$ ataxia. Brain 1976;99:207-34.

15 Farmer TW, Mustian VM. Vestibulocerebellar ataxiaArch Neurol 1963; 8:471-80.

16 Marmor MF. Hereditary vertical nystagmus. Arch Ophthalmol 1973;90:107-11.

17 Zee DS, Friendlich AR, Robinson DA. The mechanism of downbeat nystagmus. Arch Neurol 1974;30:227-37.

Requests for reprints to Dr G D Schott, The Nationa $\vec{b}$ Hospital for Nervous Diseases, Queen Square을. London WC1N 3BG. 